Review Article

\title{
Overview of Pharmacological Research Activities in North Eastern States of India in Last 5 Years
}

\author{
SUPARNA CHATTERJEE* ${ }^{*}$ and AVIJIT HAZRA \\ Department of Pharmacology, Institute of Postgraduate Medical Education \& Research, 244 Acharya J. \\ C. Bose Road, Kolkata 700 020, India
}

(Received on 16 June 2017; Accepted on 27 November 2017)

\begin{abstract}
This brief overview intends to shed light on the nature of research activities in the field of pharmacology undertaken mainly by the pharmacology departments of various medical, veterinary and pharmacy colleges from the states of Assam, Manipur, Meghalaya, Sikkim and Tripura. Both experimental and clinical pharmacological research have been undertaken but experiments on identification and validation of diverse pharmacological activities of medicinal plants used as folklore medicines in the north east have been at the forefront. Drug use surveys, disease burden estimation, drug safety monitoring and investigator initiated small scale clinical studies have enriched our knowledge. The contributions have an important bearing on the overall spectrum of pharmacology research in the country while being relevant and sensitive to the needs of the local population. Emphasis on strengthening the research infrastructure as well as building up research manpower capacity are needed to enable greater involvement of the local community in pharmacological research.
\end{abstract}

Keywords: Pharmacology; Research; North East India; Clinical Pharmacology; Experimental Pharmacology; Veterinary Pharmacology

\section{Background}

In the last five years, research in the field of pharmacology in various North east states of India has been notable. This brief overview intends to shed light on the nature of such research activities mainly undertaken by the pharmacology departments of various medical, veterinary and pharmacy colleges from the states of Assam, Manipur, Meghalaya, Sikkim and Tripura.

Both experimental and clinical pharmacological research has been undertaken but experiments on identification and validation of diverse pharmacological activities of medicinal plants have been in the forefront. Drug use surveys, disease burden estimation, drug safety monitoring and investigator initiated clinical studies have enriched our knowledge.

Research undertaken in the field of pharmacology in medical, pharmacy and veterinary institutes is primarily undertaken as postgraduate dissertation work. However, some departments have additionally conducted research projects with extramural funding. Despite various constraints in undertaking research in such settings several institutes have made significant contributions.

\section{Methodology}

The pharmacology departments of all medical colleges and some veterinary colleges of the North Eastern states of India were requested by email to provide information about their research activities in the last five years in a prescribed format. Based on the information provided by the respective departments, this overview has been compiled. However, we wish to inform the readers that the review mainly highlights the contribution from pharmacology departments of medical colleges and some veterinary institutes and is not exhaustive. Despite our sincere efforts to collate information from various sources some contributions may have been inadvertently missed out and we regret such exclusions. 


\section{Contributions from Assam}

Pharmacological research activity has been concentrated mostly in the medical colleges and to some extent in veterinary institutes. The establishment of National Institute of Pharmaceutical Education \& Research (NIPER) at Guwahati in 2008 with Gauhati Medical College (GMC) as the mentoring institute, has provided additional impetus to pharmacological and pharmaceutical work. The older medical colleges at Guwahati, Dibrugarh and Silchar offer MD seats in Pharmacology to medical students while NIPER Guwahati, in addition to MS (Pharm) Pharmacology \& Toxicology, is offering a $\mathrm{PhD}$ program in pharmacology and toxicology to students from a pharmacy background. Much of the research activity is centered around dissertation/thesis projects of the students.

\section{Experimental Pharmacology}

In recent years screening of pharmacological activity has been carried out as collaborative projects. The research groups from the institutes have excelled in the field of neuropharmacology. Exploration of neurobehavioral activity of experimental animals and ameliorative effects of various agents on abnormal neurobehavior were studied. Interesting results have emerged from studies (Jangra et al., 2016 and Sulakhiya et al., 2014, 2015, 2016) undertaken on effects of Honokiol, a lignan isolated from trees belonging to the genus Magnolia, for ameliorating stress, anxiety, depression and liver injury in animal models. Various organ toxicity ameliorating effects of natural agents such as hesperidin, silibinin and silymarin have been documented by Jangra et al. (2015). Other notable research areas include epigenetic modification studies and attenuation of oxidative stress and neuroinflammatory cascade in neurodeficit animal models. Kumar et al. (2016) undertook research on baicalein on cardiovascular oxidative stress models (Kumar et al., 2016), while Kolati et al. (2015) have demonstrated the effects of BAY 11-7082 in attenuating oxidative stress in diabetic nephropathy models. Antala et al. (2012), documented effects of Garcinia indica fruit extracts in animal models of Parkinson's disease. Ali et al. (2015), evaluated the effects of resveratrol in models of depression. The protective effect of silymarin on doxorubicin induced chronic testicular toxicity in rats was studied by Vijay et al. (2013). Sriram et al. (2013) have undertaken preliminary work on poly (ADPribose) polymerase- 1 as a potential new drug target for neurological disorders.

Pharmacological research activity in Assam Medical College, Dibrugarh, has concentrated on screening of medicinal plants (some of them indigenous to the North East) for pharmacological activity. Some of the notable ones have been antiulcerogenic activity of ethanolic extract of rhizome of Curcuma caesia and methanolic fruit extract of Musa sapientum var. paradisiaca, analgesic and acute anti-inflammatory effect of ethanolic extract of leaves of Paederia foetida, antidiabetic and antihyperlipidemic effects of ethanolic extract of leaves of Punica granatum, seed and pulp of Eugenia jambolana, bark of Terminalia arjuna and leaf extract of Ocimum sanctum, antihyperlipidemic and antioxidant activities of fruit pulp of Cassia fistula and Ipomoea aquatica and antibacterial activity of the ethanolic extracts of various plants. Psychopharmacological activity of Solanum torvum was evaluated by Paul et al. (2017).

The output from Silchar Medical College has been related to screening of pharmacological activity of indigenous medicinal plants. Anticonvulsant activity has been screened in animal models of methanolic extract of Lawsonia inermis leaves and aqueous extract of Datura stramonium leaves. Ethanolic extract of Mimosa pudica leaves has been screened for hepatoprotective and hypolipidemic activity (Purkayatha et al., 2016). Antidiabetic and renoprotective action of the ethanolic extract of Andrographis paniculata and gastroprotective and antioxidant effects of fruits of Piper nigrum have been explored in rat models at Jorhat Medical College.

\section{Clinical Pharmacology}

Investigator initiated large scale drug trials have not been undertaken during this period. However some small scale clinical trials and a large number of observational studies have been conducted in the medical colleges, mostly as component of postgraduate curricular requirements.

Faculty and students from Guahati Medical College, Guwahati, have conducted fairly detailed studies on adverse drug reactions (ADR) in HIV 
infected patients, including cutaneous ADRs. Drug use surveys have been conducted including a recently published study on prescribing pattern of analgesics in orthopedic in-patient department. The output from Silchar Medical College has been related to pharmacovigilance, prescription audits and drug use surveys in clinical settings (e.g. antihypertensives, antibiotics, antipsychotics), and also exploration of impact of ADRs on quality of life. A few small scale academic trials have also been conducted in the past few years, such as comparison of ondansetron versus granisetron in postoperative nausea and vomiting and comparison of olanzapine versus amisulpride in outpatient schizophrenia patients. Choudhury and Chakravarty (2016) profiled the antimicrobial susceptibility pattern of methicillin resistant Staphylococcus aureus isolates from patients in Silchar Medical College (Choudhury and Chakravarty, 2016).

Researchers from Jorhat medical college have conducted small scale clinical trials on preoperative antibiotic use in laparoscopic cholecystectomy and other abdominal surgeries.

An interdisciplinary study at Assam Medical College, Dibrugarh, by Dhar et al. (2012) profiled the antimicrobial resistance pattern of Klebsiella spp.

\section{Veterinary Pharmacology}

The College of Veterinary Sciences under Assam Agricultural University, Khanapara Campus, Guwahati, has kept up a steady output in validation of indigenous medicinal plants for pharmacological activity with potential veterinary as well as clinical applications. The faculty of the department have undertaken several research projects with funding from Department of Biotechnology (DBT), Indian Council of Agricultural Research (ICAR), National Medicinal Plant Board (NMBP) and Life Science Research Board (LSRB). The research group has also secured an Indian patent for a polyherbal formulation for wound healing (426/KOL/2007 A).

Antihelminthic, anticancer, wound healing, antioxidant, antistress, anxiolytic activities have been screened along with identification of their mechanistic molecular biology actions (Saikia et al., 2017). In veterinary pharmacology the work undertaken by Barua et al. (2012, 2013, 2016, 2017) have been diverse and include in vivo antimycobacterial activity of some folklore medicinal plants of north east Barua et al. $(2012,2013,2016,2017)$. Indepth studies on the antistress activity and molecular mechanism of action of the leaf extract of Elsholtzia communis in rat brain has been undertaken by Barua et al. (2017) Studies on the role of adrenergic neurotransmitters on spontaneous muscular activity in ruminant trematode has been conducted by Saikia et al. (2014).

The exploration of anticancer activity of several indigenous plant products from north east has been in focus and research groups have explored the adjuvant potential of agents like curcumin (Kumar et al., 2017), chrysin (Kasala et al., 2016) and nimbolide (Bodduluru et al., 2014) in various experimental cancer models. The effects of naringenin in cancer models by modulating CYP1A1, NFêB and PCNA expression have been demonstrated by Bodduluru et al. (2016).

The role of curcumin in preventing adverse effects of cancer chemotherapy was undertaken by Kumar et al. (2017). The research group demonstrated the beneficial role of curcumin in the prevention of cispaltin induced nephrotoxicity in 7, 12dimethyl benz[a]anthracene (DMBA) induced breast cancer model in rats.

\section{Contributions From Manipur}

The Regional Institute of Medical Sciences (RIMS), Imphal, is a premier medical institute in Manipur and has spearheaded research mainly in experimental pharmacology. The department has undertaken projects with extra mural funding from ICMR, DBT and DST (Government of India).

Experimental pharmacology research undertaken by the faculty and postgraduate students as part of their dissertation work include evaluation of various plant derived products for hepatoprotective, antidiabetic, wound healing, anticonvulsant, antiulcer and antibacterial properties in various experimental animal models (Singh et al., 2015).

In the clinical pharmacology field, Monica $\mathrm{S}$ et al. (2014) have undertaken work on antibiogram patterns of Salmonella typhi from enteric fever patients. Such studies from the region are instrumental in designing future antibiotic stewardship program. 
Research on drug assays and therapeutic drug monitoring have been initiated. The contributions in the field of drug safety monitoring in cancer patients from the regional cancer center by Gunaseelan et al. (2016) has been of great utility as ethnicity is often considered as an important risk factor towards ADR susceptibility (Gunaseelan et al., 2016; Sharma et al., 2015).

\section{Contribution from Meghalaya}

At the North Eastern Indira Gandhi Regional Institute of Health \& Medical Sciences (NEIGRIHMS), Shillong, several interdepartmental research projects, both in the field of clinical and experimental pharmacology, have been undertaken.

Pharmacoepidemiological studies of public health importance included a rabies vaccine utilization study in Meghalaya and some focused drug safety monitoring studies in elderly and in dermatology (Brahma et al., 2013; Wahlang et al., 2017). Research in the field of medical education is not much in focus but one group from NEIGRIHMS has undertaken some pilot research activities for assessment of tools for dose calculation and prescribing skills for undergraduate medical students (Das and Sarkar, 2015).

Several collaborative studies for screening of plant products for analgesic, anti-inflammatory, anticonvulsant (Lahon et al., 2015), antidiabetic and cardiovascular activities were also undertaken by the department.

\section{Contribution From Sikkim}

Research activities at the Sikkim Manipal Institute of Medical Sciences, Gangtok, are focused on both clinical and experimental pharmacology with institutional and ICMR funding.

The clinical pharmacology contributions from the institute encompass the broad research disciplines of pharmacovigilance and pharmacoepidemiology. Pandey et al. (2015) undertook a clinical study to characterize the sociodemographic profile of substance abusers in Sikkim. A drug utilization and treatment adherence study in diabetics was done by Satpathy et al. (2016). A study of public health relevance was conducted to characterize the profile of infectious disease markers in blood donors at the
Central Referral Hospital of Gangtok (Adhikari et al., 2010). Sharma et al. (2015) have undertaken pharmacovigilance and hemovigilance studies which shall serve as an important drug safety data source from Sikkim (Sharma et al., 2015).

In experimental pharmacology, collaborative research focused on screening and validation of pharmacological activity of various indigenous plant products for anti-inflammatory and anti-ulcer activities in animal models by (Tewari et al., 2014). Additional work in this field is ongoing.

\section{Contribution From Tripura}

The Agartala Government Medical College (AGMC) and Tripura Medical College \& Dr. B. R. Ambedkar Memorial Teaching Hospital, at Agartala, have initiated some research activities in the last five years.

At AGMC some interdisciplinary pilot projects have been undertaken mainly focused on disease epidemiology and drug use surveys. A clinical study was conducted for evaluating the role of gabapentin as adjuvant analgesic with opioids for neuropathic cancer pain when combined with low-dose amitriptyline in cancer patients.

Das et al. (2017) assessed the knowledge, attitude and practice of pharmacovigilance among doctors in their teaching hospital in Tripura. Clinical studies on ADR reporting trends, drug utilization in diabetic patients and generic medicine prescribing habits were undertaken (Das et al., 2017). A collaborative study on the sensitivity pattern of antimicrobials was also done. Comparative clinical studies have been undertaken with metformin versus vildagliptin.

Experimental pharmacology research activities have centered on evaluation of in-vitro antioxidant and anthelmintic, antidiabetic, hepatoprotective, laxative activities of indigenous medicinal plant products (Deb et al., 2013).

\section{Conclusion}

Review of the pharmacology related research undertaken at medical and veterinary institutes of the north east states of India suggests considerable expansion of such activity in recent years. The main focus remains on screening and validation of various 
medical plant products for pharmacological activities. Contributions from the College of Veterinary Sciences, Khanapara, and NIPER Guwahati have been vetted by the scientific community as their work has led to several publications in reputed peer reviewed national and international journals. In the field of clinical pharmacology, drug use surveys were commonly undertaken. Investigator initiated large clinical trials are yet to be undertaken. Further impetus to research can be provided by manpower training in both basic and applied research, strengthening of research infrastructure and encouraging students to take up collaborative research projects with other institutes in the country, while being sensitive to the needs of the local community.

\section{Acknowledgements}

We wish to acknowledge the following faculty of different institutes for providing us the information based on which this overview has been drafted. Prof.

\section{References}

Adhikari L, Bhatta D, Tsering D C, Sharma D K, Pal R and Gupta A (2010) Infectious disease markers in blood donors at Central Referral Hospital, Gangtok, Sikkim Asian J Transfus Sci 4 41-42

Ali S H, Madhana R M, Athira K V, Kasala E R, Bodduluru L N, Pitta S, Mahareddy J R and Lahkar M (2015) Resveratrol ameliorates depressive-like behavior in repeated corticosterone-induced depression in mice Steroids $\mathbf{1 0 1}$ $37-42$

Antala B V, Patel M S, Bhuva S V, Gupta S, Rabadiya S and Lahkar M (2012) Protective effect of methanolic extract of Garcinia indica fruits in 6-OHDA rat model of Parkinson's disease Indian J Pharmacol 44 683-687

Barua A G, Raj H, Konch P, Hussain P and Barua C C (2016) Evaluation of in vivo antimycobacterial activity of some folklore medicinal plants and enumeration of colony forming unit in murine model Indian J Pharmacol 48 526530

Barua C C, Begum S A, Barua A G, Borah R S and Lahkar M (2013) Anxiolytic and anticonvulsant activity of methanol extract of leaves of Alternanthera brasiliana (L.) Kuntze (Amaranthaceae) in laboratory animals Indian J Exp Biol 51 450-457
Mangala Lahkar of Gauhati Medical College and National Institute of Pharmaceutical Education \& Research, Guwahati; Prof. Chandana Choudhury Barua of Assam Agricultural University College of Veterinary Sciences, Khanapara campus, Guwahati; Prof. Pinaki Chakravarty of Silchar Medical College, Silchar; Prof. Meghali Chaliha of Jorhat Medical College, Jorhat; Prof. Kalpana Gohain of Assam Medical College, Dibrugarh; Prof. Chayna Sarkar of North Eastern Indira Gandhi Regional Institute of Health \& Medical Sciences, Shillong; Dr. Debasis Ray of Agartala Government Medical College, Agartala; Prof. Ranjib Ghosh of Tripura Medical College, Agartala; Prof. S Rita of Regional Institute of Medical Sciences, Imphal, and Prof. Supratim Datta of Sikkim Manipal Institute of Medical Sciences, Gangtok. We also thank Dr. Nafisha Yasmin and Dr. Shouvik Choudhury of the Dept. of Pharmacology, IPGME\&R, Kolkata, for their assistance in crosschecking the references.

Barua C C, Begum S A, Sarma D K, Pathak D C and Borah R S (2012) Healing efficacy of methanol extract of leaves of Alternanthera brasiliana Kuntze in aged wound model $J$ Basic Clin Pharm 3 341-345

Barua C C, Haloi P, Patowary P, Bora M, Barua A G, Bordoloi M $\mathrm{J}$ and Barua I C (2015) Evaluation of anti-amnestic activity of few medicinal plants in scolpolamine induced amnesia Indian J Trad Knowlspace 14 581-589

Barua C C, Talukdar A, Begum S A, Borah P and Lahkar M (2012) Anxiolytic activity of methanol leaf extract of Achyranthes aspera Linn. in mice using experimental models of anxiety Indian J Pharmacol 44 63-67

Barua C C, Talukdar A, Begum S A, Pathak D C, Sarma D K, Borah R S and Gupta A (2012) In vivo wound-healing efficacy and antioxidant activity of Achyranthes aspera in experimental burns Pharm Biol 50 892-899

Barua C C, Patowary P, Purkayastha A, Haloi P and Bordoloi M J (2017) Role of Elsholtzia communis in counteracting stress by modulating expression of hspa14, C/EBP homologous protein, nuclear factor (erythroid-derived 2)like-2 factor, Caspase-3, and brain-derived neurotrophic factor in rat hippocampus Indian J Pharmacol 49 182188

Begum S A, Upadhyaya T N, Rahman T, Pathak D C, Sarma K, 
Barua C C and Bora R S (2015) Hematobiochemical and pathological alterations due to chronic chlorpyrifos intoxication in indigenous chicken Indian J Pharmacol 47 206-211

Bodduluru L N, Kasala E R, Barua C C, Karnam K C, Dahiya V and Ellutla M (2015) Antiproliferative and antioxidant potential of hesperetin against benzo(a)pyrene-induced lung carcinogenesis in Swiss albino mice Chem Biol Interact 242 345-352

Bodduluru L N, Kasala E R, Madhana R M, Barua C C, Hussain M I, Haloi P and Borah P (2016) Naringenin ameliorates inflammation and cell proliferation in benzo(a)pyrene induced pulmonary carcinogenesis by modulating CYP1A1, NFêB and PCNA expression Int Immunopharmacol 30 $102-110$

Bodduluru L N, Kasala E R, Thota N, Barua C C and Sistla R (2014) Chemopreventive and therapeutic effects of nimbolide in cancer: the underlying mechanisms Toxicol In Vitro 28 1026-1035

Brahma D K, Wahlang J B, Marak M D and Ch Sangma M (2013) Adverse drug reactions in the elderly $J$ Pharmacol Pharmacother 4 91-94

Choudhury D and Chakravarty P (2016) Prevalence and antimicrobial susceptibility pattern of methicillin resistant Staphylococcus aureus in Silchar Medical College and Hospital, Assam, India Int J Basic Clin Pharmacol 52174 2177

Das B and Sarkar C (2015) An innovative flipped class intervention to improve dose calculation skills of phase I medical students: A preliminary study Procedia-Social Behavioral Sciences 182 67-74

Das L, Bhattacharjee P, Ghosh R, Das U K and Ray T (2017) Knowledge, attitude and practice of pharmacovigilance among doctors in a tertiary care hospital in Tripura Natl $J$ Physiol Pharm Pharmacol 7 218-223

Dhar M, Das S and Gohain K (2012) A study of occurrence of antibiotic resistance reported against Klebsiella spp. in a tertiary care hospital in Assam, India Int Res J Pharm 3 $58-60$

Deb P K, Ghosh R, Das S and Bhakta T (2013) In-vitro anthelmintic activity of Acorus calamus leaves Asian J Pharm Clin Res 6 135-137

Deb P K, Das N, Ghosh R and Bhakta T (2013) Evaluation of invitro antioxidant and anthelmintic activity of Solanum indicum Linn. berries IAJPR 3 4123-4130

Gunaseelan V, Mandal S K, Prasad V N, Khumukcham R, Devi P PV and Singh T T (2016) Adverse drug reactions to cancer chemotherapy in a regional cancer center in Northeast India
Int J Pharm Sci Res 5 3358-3363

Jangra A, Dwivedi S, Sriram C S, Gurjar S S, Kwatra M, Sulakhiya K, Barua C C and Lahkar M (2016) Honokiol abrogates chronic restraint stress-induced cognitive impairment and depressive-like behaviour by blocking endoplasmic reticulum stress in the hippocampus of mice Eur $J$ Pharmacol 770 25-32

Jangra A, Kasbe P, Pandey S N, Dwivedi S, Gurjar S S, Kwatra M, Mishra M, Venu A K, Sulakhiya K, Gogoi R, Sarma N, Bezbaruah B K and Lahkar M (2015) Hesperidin and silibinin ameliorate aluminum-induced neurotoxicity: modulation of antioxidants and inflammatory cytokines level in mice hippocampus Biol Trace Elem Res 168 462471

Jangra A, Kwatra M, Singh T, Pant R, Kushwah P, Ahmed S, Dwivedi D, Saroha B and Lahkar M (2016) Edaravone alleviates cisplatin-induced neurobehavioral deficits via modulation of oxidative stress and inflammatory mediators in the rat hippocampus Eur J Pharmacol 791 51-61

Jangra A, Kwatra M, Singh T, Pant R, Kushwah P, Sharma Y, Saroha B, Datusalia A K and Bezbaruah B K (2016) Piperine augments the protective effect of curcumin against lipopolysaccharide-induced neurobehavioral and neurochemical deficits in mice Inflammation 39 1025-1038

Jangra A, Sriram C S and Lahkar M (2016) Lipopolysaccharideinduced behavioral alterations are alleviated by sodium phenylbutyrate via attenuation of oxidative stress and neuroinflammatory cascade Inflammation 39 1441-1452

Jangra A, Sriram C S, Pandey S, Choubey P, Rajput P, Saroha B, Bezbaruah B K and Lahkar M (2016) Epigenetic modifications, alcoholic brain and potential drug targets Ann Neurosci 23 246-260

Kasala E R, Bodduluru L N, Barua C C and Gogoi R (2016) Antioxidant and antitumor efficacy of Luteolin, a dietary flavone on benzo(a)pyrene-induced experimental lung carcinogenesis Biomed Pharmacother 82 568-577

Kasala E R, Bodduluru L N, Barua C C, Madhana R M, Dahiya V, Budhani M K, Mallugari R R, Maramreddy S R and Gogoi R (2016) Chemopreventive effect of chrysin, a dietary flavone against benzo(a)pyrene induced lung carcinogenesis in Swiss albino mice Pharmacol Rep 68 $310-318$

Kasala E R, Bodduluru L N, Madana R M, V AK, Gogoi R and Barua C C (2015) Chemopreventive and therapeutic potential of chrysin in cancer: mechanistic perspectives Toxicol Lett 233 214-225

Kasbe P, Jangra A and Lahkar M (2015) Mangiferin ameliorates aluminium chloride-induced cognitive dysfunction via 
alleviation of hippocampal oxido-nitrosative stress, proinflammatory cytokines and acetylcholinesterase level J Trace Elem Med Biol 31 107-112

Kolati S R, Kasala E R, Bodduluru L N, Mahareddy J R, Uppulapu S K, Gogoi R, Barua C C and Lahkar M (2015) BAY 117082 ameliorates diabetic nephropathy by attenuating hyperglycemia-mediated oxidative stress and renal inflammation via NF- $\beta$ B pathway Environ Toxicol Pharmacol 39 690-699

Kumar M, Kasala E R, Bodduluru L N, Dahiya V and Lahkar M (2016) Baicalein protects isoproterenol induced myocardial ischemic injury in male Wistar rats by mitigating oxidative stress and inflammation Inflamm Res 65 613-622

Kumar P, Barua C C, Sulakhiya K and Sharma R K (2017) Curcumin ameliorates cisplatin-induced nephrotoxicity and potentiates its anticancer activity in SD rats: potential role of curcumin in breast cancer chemotherapy Front Pharmacol 8 132. [doi: 10.3389/fphar.2017.00132. eCollection 2017.]

Kumar P, Sulakhiya K, Barua C C and Mundhe N (2017) TNF$\alpha$, IL-6 and IL-10 expressions, responsible for disparity in action of curcumin against cisplatin-induced nephrotoxicity in rats $\mathrm{Mol}$ Cell Biochem Mar 3 [Epub ahead of print] [doi: 10.1007/s11010-017-2981-5]

Lahon J, Phukan S, Lahkar M and Sharma U (2015) Anticonvulsant potential of leaves of Psidium Guajava Linn. in MES and PTZ induced convulsion in experimental animals Int J Pharm Sci Res 6 3946-3953

Monica S, Devi K P, Devi S and Banylla S N. Antibiogram of Salmonella typhi isolated from enteric fever cases in a tertiary health care centre in Imphal Int J Pharmacol Ther 4 15-18

Pandey S K, Datta D, Dutta S, Verma Y and Chakrabarti A(2015) Socioeconomic characteristics of alcohol and other substance users, seeking treatment in Sikkim, north east India J Pharm Bioallied Sci 7 151-155

Paul P R, Gohain K and Das S (2017) Sedative and hypnotic activities of ethanolic leaves extract of Solanum torvum Sw in albino mice Int J Pharmacy Pharamceutical Res 8 $52-67$

Purkayastha A, Chakravarty P and Dewan B (2016) Evaluation of hepatoprotective activity of the ethanolic extract of leaves of Mimosa pudica Linn. in carbon tetrachloride induced hepatic injury in albino rats Int J Basic Clin Pharmacol 5 496-501

Rajput P, Jangra A, Kwatra M, Mishra A and Lahkar M (2017) Alcohol aggravates stress-induced cognitive deficits and hippocampal neurotoxicity: Protective effect of melatonin
Biomed Pharmacother 91 457-466

Saikia B, Barua C C, Haloi P and Patowary P (2017) Anticholinergic, antihistaminic, and antiserotonergic activity of n-hexane extract of Zanthoxylum alatum seeds on isolated tissue preparations: An ex vivo study Indian J Pharmacol 49 42-48

Saikia B, Barua C C, Hazarika S, Lahon L C, Saikia D, Borah R S and Verma P K (2014) Regulatory role of adrenergic neurotransmitters on the spontaneous muscular activity in the ruminant trematode Paramphistomum cervi (Paramphistomatidae) J Helminthol 88 357-361

Satpathy S V, Datta S and Upreti B (2016) Utilization study of antidiabetic agents in a teaching hospital of Sikkim and adherence to current standard treatment guidelines J Pharm Bioall Sci 8 223-228

Sharma D K, Datta S and Gupta A (2015) Study of acute transfusion reactions in a teaching hospital of Sikkim: A hemovigilance initiative Indian J Pharmacol 47 370-374

Singh O J, Devi N M, Prasad V N, Jamoh A, Bhattacharjee P and Rita S (2015) Analgesic activity of aqueous extract of Eryngium foetidum Linn Int J Pharm Bio Sci 6 201-207

Sriram C S, Jangra A, Kasala E R, Bodduluru L N and Bezbaruah B K (2014) Targeting poly(ADP-ribose) polymerase1 in neurological diseases: A promising trove for new pharmacological interventions to enter clinical translation Neurochem Int 76 70-81

Sriram C S, Jangra A, Madhana R M, Gurjar S S, Mohan P and Bezbaruah B K (2015) Multiple facets of poly(ADPribose) polymerase-1 in neurological diseases Neural Regen Res 10 49-51

Sulakhiya K, Keshavlal G P, Bezbaruah B B, Dwivedi S, Gurjar S S, Munde N, Jangra A, Lahkar M and Gogoi R (2016) Lipopolysaccharide induced anxiety- and depressive-like behaviour in mice are prevented by chronic pre-treatment of esculetin Neurosci Lett 611 106-111

Sulakhiya K, Kumar P, Gurjar S S, Barua C C and Hazarika N K (2015) Beneficial effect of honokiol on lipopolysaccharide induced anxiety-like behavior and liver damage in mice Pharmacol Biochem Behav 132 79-87

Sulakhiya K, Kumar P, Jangra A, Dwivedi S, Hazarika N K, Baruah C C and Lahkar M (2014) Honokiol abrogates lipopolysaccharide-induced depressive like behavior by impeding neuroinflammation and oxido-nitrosative stress in mice Eur J Pharmacol 744 124-31

Tewari B, Devi M N, P Devi S and Thankgkhiew B (2014) Antiulcer effect of the aqueous extract of Gynura cusimba (D.Don) Moore on aspirin plus pylorus ligation model in albino rats Int J Pharm Bio Sci 5 77-84 
Vijay Kranti M, Mahesh V, Srinivas P, Ganesh Y V, Ajay Godwin $P$ and Lahkar M (2013) Evaluation of the protective effect of silymarin on doxorubicin induced chronic testicular toxicity in rats Int J Pharma Bio Sciences 4 473-484
Wahlang J B, Laishram P D, Brahma D K, Sarkar C, Lahon J and Nongkynrih B S (2017) Adverse drug reactions due to cancer chemotherapy in a tertiary care teaching hospital Ther Adv Drug Saf 8 61-66. 